\title{
BOA EDUCAÇÃO E BUSCA PELOS PRINCÍPIOS NO LIVRO I DA ÉTICA NICOMAQUEIA (EM) DE ARISTÓTELES ${ }^{1}$
}

\author{
Priscilla Spinelli \\ Universidade Federal do Rio Grande do Sul
}

\begin{abstract}
Resumo: Buscando apresentar uma interpretação para EN I 4 1095a31-b13, este artigo defende que a digressão nela feita por Aristóteles pretende caracterizar a investigação recém iniciada como promissora, opondo-a, ainda que não explicitamente, ao modo rígido socrático-platônico de fazer Ética ou Política. Para tanto, propõe-se uma interpretação pouco usual do termo que (hoti) como o princípio buscado e não como ponto de partida da investigação. Recusa-se igualmente ver na passagem mencionada uma referência ao modo ou etapas de aquisição de virtude moral ou prudência (phronesis), mas de um corpo preciso de conhecimento ou ciência, a Ética ou Política.
\end{abstract}

Palavras-chave: Investigação ética, princípios, boa educação.

Abstract: In order to provide an interpretation for NE I 4 1095a31-b13, this paper argues that Aristotle's digression in that section serves to characterize the recently started research as promising, opposing it, although not explicitly, to the rigid Socratic-Platonic way of doing Ethics or Politics. To this end, a somewhat novel interpretation of the term that (hoti) is proposed, according to which it refers to the principle sought for, and not to the startingpoint of the research. This interpretation also refuses to see a reference, in the mentioned passage, to the form of acquisition of moral virtue or prudence (phronesis), replacing it by a reference to the acquisition of a body of knowledge or science, the Ethics or Politics.

Keywords: Ethical research, principles, good education

1 Excetuando a Física (de Lucas Angioni) e a Ética Eudêmia (em versão provisória e inédita, de Inara Zanuzzi e Raphael Zillig), as passagens citadas de trechos das obras de Aristóteles são versões minhas das traduções listadas nas Referências bibliográficas. 


\section{Introdução}

Nos dois primeiros capítulos da $E N$, Aristóteles apresenta o objeto cujo conhecimento será buscado pela investigação em questão e o ramo do conhecimento que dele se ocupará. Trata-se, respectivamente, do bem supremo para o ser humano, no capítulo 4 identificado com a felicidade (eudaimonia), e da Política. Os capítulos 3 e 4 são conhecidos por conterem pelo menos três observações importantes. A primeira é acerca da exatidão a ser buscada nessa investigação. Afirma Aristóteles que a exatidão a ser exigida em uma investigação deve acompanhar a natureza do objeto estudado; ao pretender conhecer o que é o bem para o ser humano, o que vem a ser a melhor vida possível para nós, adentramos um terreno cheio de incertezas e inconstâncias. Seres humanos são seres capazes de decidir e agir por razões, o que possibilita tipos de vida e comportamentos os mais variados e antagônicos. Além disso, dada certa contingência imanente ao mundo, o resultado do que fazemos não é sempre e necessariamente o mesmo. O que é bom para nós humanos carrega, assim, um grau elevado de indeterminação; a investigação a ser feita sobre isso herda essa indeterminação. Aristóteles acredita, no entanto, que algo de certo, objetivo e necessário pode ser dito sobre o que é bom para nós, desde que não se esqueça que o procedimento a ser adotado e o resultado a ser dele obtido devem acompanhar as características do objeto investigado.

A segunda observação importante é sobre os pré-requisitos necessários àquele que será um bom estudante do bem humano. Ele não pode ser muito jovem, pois já deve saber julgar razoavelmente bem sobre esse assunto, vindo em virtude disso a julgar bem acerca do avanço e resultados obtidos na investigação sobre o bem humano. Ele precisa, portanto, ter experiência acerca das ações. Não pode ser imaturo quanto ao caráter, tampouco; uma vez que a investigação sobre a boa vida pretende ajudar a conduzi-lo na sua direção, se ele atende unicamente aos seus desejos ou não se atém ao que se propõe por deliberação fazer, sendo por isso acrático, estudar essas coisas não será capaz de conduzi-lo de forma alguma.

A terceira observação é aquela sobre como devemos proceder ao iniciar uma investigação. Tendo aprendido com Platão que a tarefa do filósofo é explicar como e por que as coisas são do modo como elas nos aparecem - e, se o modo como elas nos aparecem não corresponde ao modo como elas realmente são, então sua tarefa será explicar como elas realmente são e por que elas nos aparecem de outro modo e não do modo como elas 
são -, Aristóteles sugere que comecemos pelas aparências ou fenômenos (phainomena). Trata-se de salvar as aparências (tithenai ta phainomena ${ }^{2}$ ), aquilo que nos é dado ou é aparente (não necessariamente aquilo que é ilusório; se esse for o caso, é algo que precisa ser mostrado e explicado), na medida em que as explicamos. Muitas vezes o modo com as coisas nos aparecem são relatadas ou sustentadas através de opinióes, no caso, sobre o maior bem para o ser humano, a boa vida, a felicidade ${ }^{3}$. Devemos começar a investigar o bem supremo examinando não todas as opiniões possíveis e sustentadas, mas as endoxa, i.e., as opiniões reputadas, dignas de serem consideradas, pois são predominantes e/ou arguíveis ${ }^{4}$. Poderemos então, examinando essas opiniões, chegar a um esclarecimento maior do que é o bem supremo para o ser humano ou, pelo menos, do que ele não é.

O modelo de investigação filosófica sobre o bem de que Aristóteles dispõe é o modelo socrático-platônico. O que podemos observar nos diálogos de Platão é a busca incessante de Sócrates pela definição de um termo ${ }^{5}$. A personagem Sócrates buscava, assim, pelo princípio ou causa e julgava acertadamente, aos olhos de Aristóteles - que esclarecê-lo lançaria luz sobre tudo o mais que dele depende. Sócrates se mostra sempre insatisfeito com os resultados obtidos nos seus questionamentos e parece incansável na busca por outros melhores: se uma objeção ou um contra-exemplo puder ser apresentado à definição que está sendo discutida, então ela deve ser abandonada e uma melhor, imune a objeções, precisa ser encontrada.

Uma grande quantidade de diálogos platônicos termina de modo aporético, inconcluso, em dificuldades. Trata-se dos diálogos que chamamos de socráticos, os quais acolhem o procedimento adotado por Sócrates e finalizam de um modo, porque não dizer, frustrante: analisamos muitas ideias, consideramos muitas posições, argumentamos pelo sim e pelo não, mas nenhuma boa definição foi encontrada. Sócrates parece não tomar

\footnotetext{
${ }^{2}$ Cf. OWEN, 1975.

${ }^{3}$ Como Owen nota, os fenômenos da física e da ética são sobretudo opiniões sustentadas acerca dos seus objetos; no caso da biologia e da meteorologia, os fenômenos são sobretudo dados observados empiricamente (cf. OWEN, 1975, p. 114).

${ }^{4}$ Nos Tópicos Aristóteles apresenta as endoxa como "opiniões de todos, da maioria ou dos mais sábios - e, dentre os sábios, de todos, da maioria ou dos mais sábios e reputados" (Top. 11 100b22-23).

${ }^{5}$ Algo pelo qual Aristóteles o tem em grande conta, tendo assim Sócrates contribuído imensamente para 0 avanço da filosofia (cf. Metafísica A 6 e 9). O que Sócrates busca é pelo um na multidão, um definição que abranja todas e apenas as coisas que estão sendo definidas (coisas pias, corajosas, justas, belas, virtuosas, conhecidas, etc.; cf. IRWIN, 1995, p. 23).
} 
nenhuma decisão diante dos dilemas conceituais que enfrenta. Não encontramos, assim, algo positivo e, afora a conclusão de que pelo menos temos mais consciência de que realmente não sabemos a respeito do que investigávamos - dizendo com Sócrates que "só sabemos que nada sabemos" -, temos a nítida impressão de sairmos da investigação sem nada saber.

É bem verdade que os diálogos platônicos considerados maduros e de velhice não finalizam dessa forma, sendo mais propositivos. Em todo o caso, mesmo na República temos um Sócrates que não se atreve a dizer o que é o Bem, a Ideia cujo conhecimento traria luz a tudo o mais - pois ela é causa de tudo o mais e tudo o mais dela depende -, utilizando-se de alegorias e metáforas para explicá-lo: o Bem é comparado ao sol, as faculdades e as realidades são representadas com linhas, o processo de conhecimento é descrito como o sair de um lugar escuro e obscuro, uma espécie de caverna, subindo e avançando em direção ao sol ${ }^{6}$. Platão procede dessa forma, assim parece, para explicar realidades que a nossa linguagem não consegue - ou pelo menos não consegue ainda - diretamente espelhar.

Assim, se, por um lado, a partir de certo momento da sua obra Platão não se furta mais de fornecer uma abordagem acerca de como as coisas são oferecendo, com efeito, uma explicação para o fato de elas serem realmente diferentes do modo como nos aparecem -, por outro, não buscar esclarecê-las com uma linguagem direta parece revelar certo desapontamento com as suas investidas diante do que é uno, absoluto, perfeito, imutável, i.e., as Ideias, em especial a Ideia de Bem. As mazelas do mundo não terão fim enquanto os reis não se tornarem filósofos ou os filósofos reis ${ }^{7}$. E o que se precisa é ter dessa Ideia um conhecimento também ele uno, absoluto, perfeito, imutável. A inspiração aqui é parmenídica, o modelo de conhecimento é o matemático: toda pretensão científico-filosófica que não alcança o grau de precisão da matemática - que deveria ser conhecida para adentrar a Academia! - não pode, por isso mesmo, ser chamada ciência, conhecimento. O procedimento descrito na caverna pode ser entendido como um abandono de tudo aquilo que é dado pelos sentidos: a busca é por aquilo que é puramente inteligível, não podendo ter origem no ou ser derivado da experiência, que só é capaz de atestar o mutável, composto, instável, relativo. É preciso, com efeito, afastar-

${ }^{6}$ Cf. República, livros VI (506d-509c; 509d-511e) e VII (514a-518d).

${ }^{7}$ Cf. Rep. V, 473c-e. 
se do que ela nos fornece para ascender ao inteligível e apreender o que realmente é.

Acredito que ao tecer as observações iniciais na $E N$ sobre os procedimentos a serem adotados Aristóteles pretende entre outras coisas posicionar-se diante do modelo socrático-platônico esboçado vaga e grosseiramente acima, apresentando pontos em que se aproxima e pontos em que se afasta dele. No que segue concentrarei minha análise no trecho final do capítulo 4 do livro I da $E N$, a saber 1095a33-b13. Trata-se do momento em que Aristóteles fala da sua investigação como uma busca pelos princípios, sendo a pertinência dos procedimentos e o seu sucesso adequadamente observados e julgados apenas por aquele que tenha sido "educado nos bons hábitos”. Acredito que aqui o principal objetivo de Aristóteles é caracterizar a sua empreitada filosófica como digna e promissora, justamente porque parte da e não se separa da experiência daquele que a segue. $\mathrm{O}$ conhecimento do bem humano possível e alcançável, não sendo abstrato nem puramente racional, mas sendo dependente da experiência na virtude do estudante.

\section{A busca pelos princípios}

O que se quer conhecer através da investigação presente na $E N$ é o bem supremo para o ser humano. Todos concordam que este bem é a felicidade (cf. 1095a17), a melhor vida que um ser humano pode ter, mas essa concordância parece ser puramente verbal, pois variam muito as opiniões sobre o que ela é. Um exame das opiniões predominantes ou arguíveis deverá feito a fim de avançar na investigação que busca conhecer o bem supremo, conclui Aristóteles (cf. 1095a30). Ele faz então uma observação acerca dos rumos da investigação recém iniciada:

\footnotetext{
"Não deixemos de notar que há uma diferença entre argumentos que partem dos princípios e que se dirigem aos princípios. Platão também estava certo ao fazer essa questão, perguntando se estávamos no caminho que parte dos ou que se dirige aos princípios, pois há aí uma diferença assim como há em uma pista de corrida entre o caminho que vai dos juízes até o ponto de retorno e o caminho de volta." (1095a31-b1)
}

Aristóteles pergunta, atribuindo os créditos dessa indagação a Platão, se a investigação em questão está partindo dos ou indo em direção aos 
princípios: é importante ter clareza acerca da direção que estamos tomando. Ora, estamos indo na direção dos princípios, i.e., estamos buscando esclarecer aquelas coisas que hão de lançar luz sobre tudo o mais nesse assunto, tendo o poder de explicar e justificar tudo o mais que delas depende; estamos buscando conhecer não um bem qualquer, mas $o$ bem supremo. $\mathrm{O}$ outro caminho consistiria em partir dos princípios, sendo estes já conhecidos, rumo à demonstração do que deles depende, o que se faz, por exemplo, ao demonstrar teoremas na geometria. Essa etapa da busca dos princípios quando eles não são ainda conhecidos revela-se, assim, imprescindível: é apenas conhecendo-os que podemos, como afirma Aristóteles no trecho citado acima, percorrer "o caminho de volta", i.e., não só conhecer as realidades mais fundamentais de um certo domínio, mas ser capaz de mostrar como essas realidades explicam as demais coisas que delas dependem, e mostrar que, por cumprirem essa função, elas são de fato realidades fundamentais ${ }^{8}$.

Que esta seja a direção adotada na investigação justifica que a comecemos com o que nos é mais conhecido ou cognoscível, familiar ou evidente, aquilo com o que já temos contato e somos capazes de lidar mais facilmente. Afirma Aristóteles: "devemos começar com o que é mais conhecido, mas as coisas são mais conhecidas de dois modos: umas o são para nós, outras o são sem mais. Presumivelmente, nós devemos começar com o que nos é mais conhecido" (EN 1095a2-4). Se um conhecimento novo só pode ter lugar a partir de um conhecimento pré-existente, como Aristóteles afirma no início dos Segundos Analíticos, então é preciso começar com o que já conhecemos, avançando a partir disso na direção do que queremos conhecer e que é mais conhecido sem mais.

O mesmo tipo de observação é feito no início da Física. Aristóteles afirma que em todo ramo do conhecimento que tem princípios, o conhecer se dá através do reconhecimento dos princípios, do que é primeiro e mais fundamental no terreno investigado, e que a primeira coisa a ser feita é determiná-los (cf. 184a10-15). E acrescenta:

\footnotetext{
${ }^{8}$ Sigo aqui uma sugestão de Richard Kraut: trata-se de entender não apenas que ir até o ponto de retorno não é o mesmo que voltar até os juízes mas que depois de ir até o ponto de retorno é preciso voltar até os juízes. 0 exemplo da pista de corrida, segundo Kraut, chama a atenção para o fato que devemos não apenas ir em direção aos princípios, mas fazer o caminho de volta, mostrando como eles são capazes de explicar as coisas que deles dependem (cf. KRAUT, 2009, p. 88).
} 
"Tal percurso naturalmente vai desde o que é mais cognoscível e mais claro para nós em direção ao mais claro e mais cognoscível por natureza, pois não são as mesmas coisa que são cognoscíveis para nós e cognoscíveis sem mais. Por isso, é necessário, desse modo, proceder das coisas que, apesar de serem menos claras por natureza, são mais claras para nós, em direção às mais claras e mais cognoscíveis por natureza.” (184a16-20)

Devemos começar com o que nos é mais conhecido, aquilo que nos aparece de forma mais evidente e, assim, buscar um conhecimento daquilo que, embora seja mais conhecido por natureza ou sem mais (haplos), não o é, ainda, para nós (hẹmin). Trata-se de começar com as aparências, os fenômenos, aqueles dos quais nos cabe enquanto filósofos "salvar", i.e., buscar uma explicação adequada.

A exposição desse procedimento, tanto na Ética quanto na Física, parece uma explicação para o fato de Aristóteles dar início a sua investigação através de um exame das opiniões reputadas, as endoxa, "aquelas que são predominantes ou que parecem ser arguíveis” (cf. 1095a30). Se a investigação ética (ou física) segue como um todo esse método, isso não me importa aqui. O que me importa observar é apenas que é desse modo que Aristóteles começa a sua investigação: considerar as opiniões reputadas é parte importante da busca pela verdade em um determinado domínio (ainda que não seja, talvez, tudo o que se deva fazer para encontrá-la), pois a isso correspondem as coisas que, neste domínio, temos previamente contato e são portanto para nós mais conhecidas ${ }^{9}$.

A via pela qual temos contato com as opiniões reputadas sobre um determinado assunto é a experiência. Aristóteles não afirma muitas coisas sobre ela na $E N^{10}$. Mas diz por exemplo que é por faltar experiência aos

\footnotetext{
${ }^{9} \mathrm{~A}$ disputa à qual implicitamente me refiro é aquela entre os que defendem e os que negam que o método aristotélico em seus tratados seja o dialético. Para um apanhado compreensivo das possíveis posições (que abrangem um espectro amplo e gradativo, nem de longe se resumindo a uma questão de ser a favor ou contra) em relação a essa disputa, cf. SIM,1999. A introdução feita por May Sim é bastante esclarecedora.

10 Um trecho inicial da Metafísica aponta para uma regra que aprendemos a aplicar porque foi aprendida a partir de memórias de casos semelhantes, a qual relaciona necessariamente duas coisas, sem dar conta da sua causa. É assim que, por ter visto frequentemente que o remédio $x$ curou $y, w e q$, que tinha doença $z$, posso concluir que $x$ curará a doença $z$ de $r$ e, em geral, que $x$ cura $z$, sem saber, no entanto, por que isso é assim (a saber, porque tais pessoas têm uma constituição assim e assim, o remédio $x$ tem tais e tais propriedades que combatem z, que é assim e assado). Quando o porquê é acrescentado, tem-se arte (cf. Met. A 1981a1-13).
} 
jovens que eles não serão bons estudantes das lições presentes na $E N$; mais adiante, no livro VI, dirá que devemos atentar aos conselhos também dos homens experientes, pois ele têm um olho através do qual enxergam bem (cf. 1143b12-15). Se é verdade que cabe ao filósofo - no caso, ao filósofo prático, ao filósofo moral - oferecer uma explicação das aparências, é preciso que estas apareçam para aquele que segue na investigação. Apenas assim elas realmente serão um ponto de partida para a busca da verdade, e esta será apreendida enquanto tal por aquele que a busca. Creio que é a isso que Aristóteles faz referência quando, ao exigir experiência dos seus alunos, afirma que "as discussões [presentes na $E N$ ] partem disso e são sobre isso", a saber, as "ações que ocorrem na vida" (cf. 1095a3). Estas são as aparências das quais a investigação ética parte e as quais é preciso explicar. Trata-se não apenas das ações que o próprio aluno realiza, das que ocorrem na sua vida, mas das que ocorrem na vida das demais pessoas (cf. 1095a2-3). É preciso então ter contato com esses variados tipos de vida, observando como as pessoas vivem e o que elas alegam como sendo a boa vida. Se somos todos igualmente racionais, não erramos totalmente ao buscar a verdade ${ }^{11}$ - ainda que não a alcancemos necessariamente apenas por isso -; consequentemente, deve ser possível encontrar parcelas suas em todas as opiniões plausíveis, predominantes ou minimamente arguíveis. Começar por essas opiniões ajudará a ascender ao princípio que as explicará, revelando, assim, o que cada uma delas tem de verdadeiro.

Algo que não está explícito na Ética e que explica a adoção desse procedimento parece mais claro em um trecho dos Primeiros Analíticos. Ter contato com as aparências, com os fenômenos, é estar pelo menos potencialmente de posse dos princípios, das realidades mais fundamentais de um determinado domínio. Em Prim. An. I 30, Aristóteles afirma o seguinte:

“(...) é tarefa da experiência fornecer os princípios que pertencem a cada assunto. Quero dizer, por exemplo, que a experiência astronômica fornece os princípios da ciência astronômica; pois, uma vez que os fenômenos foram adequadamente apreendidos, as demonstrações da astronomia foram descobertas. Similarmente ocorre com toda outra arte ou ciência. Consequentemente, se os atributos da coisa foram

\footnotetext{
${ }^{11}$ Cf. Met. a 1 993a27-b7.
} 
apreendidos, nossa tarefa será então prontamente exibir as demonstrações. Pois, se nenhum dos atributos da coisa foram omitidos na investigação, seremos capazes de descobrir a prova e demonstrar tudo o que admite prova, e tornar claro aquilo cuja natureza não admite prova." (Grifos meus, 46a17-26)

A experiência de um determinado conjunto de coisas fornece, então, os princípios a partir dos quais poderemos compreender tudo o mais desse conjunto. Aquele que tem a experiência relevante de algo, tem, por isso, os seus princípios. Isso significa que as causas ou explicações dos fenômenos apreendidos já são potencialmente conhecidos por ele. Disso não se segue, no entanto, que nenhuma tarefa investigativa seja necessária a fim de que ele se aperceba de que são estes os princípios, como eles funcionam enquanto tais, qual a sua função em seu domínio. É preciso compreendê-los como princípios, esclarecendo-os e localizando-os na base de uma estrutura explicativa. Tendo experiência astronômica, o estudante poderá localizar adequadamente o que nas suas provas e demonstrações serão os princípios, apontando a realidade mais fundamental da qual as demais realidades dependem. O "o que não admite prova ou demonstração" nessa estrutura são supostamente os próprios princípios, pois são causa primeira e deles depende tudo o mais, mas eles não dependem, derivativa ou demonstrativamente, de nada. O que são os princípios e como eles têm poder explicativo é algo que o estudante precisará mostrar na sua exposição, tornando clara, assim, a sua natureza. O mesmo vale para a ética, se vale, como Aristóteles afirmou no treco citado acima, para "toda outra arte e ciência".

Creio que Aristóteles tem algo desse tipo em mente quando afirma na $E N$, após observar que devemos começar com o que é mais conhecido para nós, que

“(...) aquele que há de ouvir de maneira adequada as lições sobre o que é nobre e justo e, em geral, sobre política, deve ter sido educado nos bons hábitos. Pois o que é um princípio, e se este estiver suficientemente claro, ele não precisará de um porque. E aquele que se encontra em tal condição possui ou pode facilmente apreender os princípios.” (1095b4-8) 
A educação nos bons hábitos, aliada à clareza na exposição de um princípio, parece suficiente para que o estudante entenda que certas coisas (os princípios) são de um certo modo, as localize e compreenda sua função, sem que ele exija como necessária a apresentação de um porque detalhado, de uma demonstração do que elas são. Sendo tais coisas primeiras, obter delas uma demonstração seria apresentar um argumento em que suas premissas estariam por realidades mais fundamentais, os princípios ou causas, das quais essas coisas primeiras derivariam. Isso implicaria admitir que há realidades mais fundamentais que aquelas que estamos querendo esclarecer. No entanto, se os princípios não admitem prova ou demonstração precisamente porque são princípios $^{12}$, buscá-la ou exigi-la será algo próprio daqueles que, por não terem recebido a educação adequada, não são capazes de julgar corretamente acerca do que é e do que não é adequado exigir. Não entenderão que cabe buscar esclarecimento do significado, elucidar a função e o poder explicativo dos princípios, mas não procurar a sua demonstração, pois ela não existe.

Ter "experiência nas ações que ocorrem na vida”, exigência presente em ENI 3 1095a3, não é o mesmo que "ter sido educado nos bons hábitos", conforme ocorre no trecho citado acima. No entanto, essas duas exigências se complementam. Se, de um lado, é preciso ter experiência para ter o contato com as aparências ou fenômenos que, sendo o que é "o mais conhecido para nós", permitirão o avanço em direção ao que é "o mais conhecidos sem mais" ou os princípios, de outro, para reconhecer a adequação e pertinência do estabelecimento dos princípios, é preciso ter sido educado nos bons hábitos. Essa boa educação recobre pelo menos dois aspectos, os quais Aristóteles aparentemente não distinguiu nesse trecho. Um deles diz respeito a uma capacidade intelectual teórica: trata-se de reconhecer, por ter experiência no assunto, quando um argumento é adequado ou não, suficiente ou deficiente, quando as premissas são próprias e não estranhas ou alheias ao assunto $^{13}$. O vocabulário utilizado aqui por Aristóteles deixa claro que a sua

${ }^{12} \mathrm{Cf}$. Segundos Analíticos I 3, especialmente 72b19-24.

${ }^{13}$ Estou apontando aqui para o procedimento ilícito de passagem de um gênero a outro; as conclusões e as premissas de um argumento devem ser homogêneas (cf. Segundos Analíticos I 6 74b24-26; I 7 75a38-b8). Gerardo Mosquera apresenta da seguinte forma os argumentos que operam a partir de noções "comuns" (koinal), os argumentos logikoi: "(...) em virtude da ausência do objeto próprio, segue-se que o argumento logikos não é demonstrativo. (...) Segue-se também que o argumento logikos será válido apenas se a conclusão for ela também "comum", se não ela constituirá uma transgressão de gênero. (...) Não se pode, por exemplo, a partir de um princípio do domínio da física estabelecer uma conclusão do domínio da ética, nem a partir de uma premissa "comum" estabelecer uma conclusão do domínio da física ou da ética" (cf. MOSQUERA, 1998, p. 41- 
audiência tem alguma destreza com conceitos e termos científicos, que estão habituados a aventurar-se em investigações, que seus estudantes sabem quem é o Platão que acertou ao questionar se partimos dos ou nos dirigimos aos princípios.

O outro aspecto, mais enfatizado pelos comentadores de Aristóteles, é o aspecto moral dessa boa educação exigida, o qual é quase sempre salientado como indispensável para tirar proveito prático da investigação ética ${ }^{14}$. É possível entender que exigir educação nos bons hábitos, i.e., em hábitos moralmente bons, não tem a ver com ser capaz ou não de compreender as lições oriundas dessa investigação ${ }^{15}$. Em relação a isso ela avança do mesmo modo que qualquer outra disciplina teórica e as capacidades exigidas para seguir as suas lições são as mesmas exigidas para seguir qualquer investigação. A exigência aristotélica da boa educação moral teria a ver, assim, com ser capaz de, tendo compreendido corretamente essas lições, adotar práticas conformes a essa compreensão. Seria por isso que aquele que é jovem e imaturo quanto ao caráter e aquele que é acrático não seriam capazes de estudar proveitosamente o bem supremo: entenderiam o que ele é, mas não seriam capazes de, a partir do conhecimento adquirido, buscar realizá-lo (cf. 1095a6-9).

Acredito que essa descrição da função da boa educação moral no estudo do bem supremo esteja parcialmente correta. A meu ver, direcionar a vida na direção apontada pelas lições presentes na $E N$ é a parte mais importante do que significa precisamente compreendê-las, e não algo que se acrescenta a sua compreensão ${ }^{16}$. E que esse estudo tenha influência na ação

42). É interessante para os meus propósitos neste texto observar que Mosquera aponta para o fato de Aristóteles ter julgado logikoi os argumentos de Platão e o seu procedimento investigativo, o que o teria levado à - equivocada, aos olhos de Aristóteles - teoria das Ideias (MOSQUERA, 1998, p. 43; cf. também p. 45). É na Metafísica que Aristóteles afirma que "os pensadores atuais [os platônicos] tendem a classificar os universais como substâncias, pois os gêneros são universais, e estes eles tendem a descrever como princípios e substâncias devido à natureza abstrata [logikos] da sua investigação" (Met. $\Lambda 1$ 1069a26-28).

14 "(...), pois o fim visado não é o conhecimento, mas a ação" (EN I 3 1095a5); "Dado então que a presente investigação não visa ao conhecimento teórico como as outras (pois estamos investigando não a fim de saber o que é a virtude, mas para nos tornarmos virtuosos, pois de outro modo nosso estudo seria inútil) (...)", (EN II 2 1103b26-29).

15 Um interpretação nessa direção é sugerida por IRWIN, 1978, p. 262 e nota 30; cf. também p. 271-272.

${ }^{16}$ Talvez isso seja válido apenas para o acrático, que é justamente aquele que, tendo consciência do que deve fazer, age contrariamente a isso. De qualquer forma, não é fácil determinar o que seria agir em conformidade com as lições da $E N$ dada, por exemplo, a generalidade do que poderíamos chamar de conselhos presentes na EN; tampouco creio haver espaço aqui para justificar adequadamente a minha posição sobre 0 assunto, o que pretendi ter feito em outro momento (cf. SPINELLI, 2010). 
de quem o realiza é o objetivo principal para nele adentrar. Contudo, não creio que isso esteja em questão na passagem citada acima (a saber, 1095b4-8). Uma boa educação moral é indispensável para que o estudante das lições éticas compreenda adequadamente a natureza, o limite e o alcance das afirmações e argumentos acerca daquilo que está sendo estudado. Ele sabe, ainda que talvez parcialmente e sem nenhuma clareza conceitual e filosófica, o que é uma boa vida, o que é ser feliz. Ele tem, por isso, bons critérios para julgar com propriedade sobre o que quer que sobre isso seja afirmado. Ele será, assim, capaz de reconhecer a veracidade das teses presentes na $E N$ e a adequação dos argumentos que pretendem justificá-las.

Como ficará claro no decorrer da $E N$, ser feliz não é ser virtuoso, mas viver virtuosamente é a principal parte de ser feliz. Assim, se é verdade que a experiência em um determinado assunto é capaz de fornecer os princípios naquele assunto e, como será visto em $E N$ I 7, o bem supremo consiste principalmente em atividade virtuosa da alma (racional), então é preciso que o estudante do bem supremo tenha experiência na atividade virtuosa. Conhecendo através da prática a sua importância na vida feliz, o estudante saberá reconhecer quando as definições e argumentos adequados forem apresentados.

Penso que é exatamente isso o que acontecerá em EN I 7 em relação ao argumento da função própria e à definição de eudaimonia que dele resulta, momento da $E N$ que deve ser ligado diretamente ao trecho de I 4 citado anteriormente (cf. 1095b4-8). Não acredito, assim, que esteja correta a afirmação segundo a qual mesmo um Trasímaco ${ }^{17}$ poderia concordar com a conclusão do argumento da função própria. Essa posição é sustentada por Gavin Lawrence: "O argumento [da função própria] é obviamente formal no sentido em que visa a apenas fornecer um "delineamento do bem" (...). Assim, um imoral como Trasímaco na República de Platão, que considera a injustiça como uma excelência humana, pode concordar com a sua conclusão"18. Sigo, antes, o que propõe Myles Burnyeat:

\footnotetext{
17 Personagem da República de Platão que no final da sua argumentação defende uma inversão total de valores em que a injustiça é considerada uma coisa prudente e boa, sendo a justiça uma "sublime ingenuidade" (cf. República I 348c-349a).

${ }^{18}$ Cf. LAWRENCE, 2009, p. 55. Tendo a ver a tentativa de Lawrence de salvar Aristóteles do comprometimento com uma metafísica inaceitável como excessivamente formal, enfraquecendo, por exemplo, a força e o papel da exigência de boa educação por parte do estudante. Nesse caso, essa exigência poderia ser entendida como necessária para que o estudante venha a realizar aquelas coisas que com a EN ele compreendeu; mas como seria possível essa "aplicação" dada a ausência completa de conteúdo defendida por Lawrence a fim de tornar a
} 
"Não se trata de um argumento que comoveria qualquer pessoa que de fato duvide ou nega que deva praticar as virtudes - o que é claro nas páginas finais do livro I da República de Platão, onde Trasímaco permanece em absoluto imoto ante uma versão platônica desse argumento [da função própria] -, mas de um argumento que tenha algo a dizer ao entendimento reflexivo de alguém com as preocupações morais básicas que Aristóteles pressupõe em sua audiência."19

A admissão que: 1) o homem tem uma função que lhe é própria, a atividade racional, e 2) o bem de algo reside na excelente realização da sua função implicam o comprometimento com uma resposta única e objetiva à questão "como devemos viver?", ou seja, implica 3) a conclusão do argumento da função "atividade da alma (racional) segundo perfeita virtude" (cf. o argumento da função própria, EN I 7 1098a7-18). Um amoral, um imoral, um relativista ou um subjetivista não pode estar disposto a aceitar que há algo como 3), uma resposta válida, objetiva, única e a mesma para todo ser humano. E, ao ver que a aceitação de 1) e 2) leva inevitavelmente a 3), provavelmente as recusaria no seu conjunto. Não estou dizendo que essa seria a única razão para recusar como um todo o argumento da função própria - como tampouco se segue do que afirmei que se alguém nega essas coisas, então ele é um amoral, imoral, relativista ou subjetivista -, mas que o sujeito que não recebeu uma boa educação moral provavelmente recusará tais premissas e a sua conclusão precisamente quando se der conta do ponto de vista objetivo que elas requerem e implicam.

Uma sugestão interessante sobre isso é dada por Richard Kraut ${ }^{20}$. Podemos pensar no bom estudante da $E N$ como uma pessoa que já vive relativamente bem e está realmente querendo aprender mais sobre como viver da melhor forma. Ela tem algumas ideias - e algumas boas ideias - de como isso deve se dar, mas quer aprender mais e mais profundamente sobre isso. E, na medida em que, analisando os argumentos "de mente aberta" ${ }^{21}$, sem nenhum problema em adotar uma perspectiva objetiva, ela descobrir algo

empreitada aristotélica uma empreitada razoável? A despeito disso, sua tentativa nesse artigo é digna de nota e lança luz de maneira compreensiva ao projeto aristotélico na $E N$.

${ }^{19} \mathrm{Cf}$. BURNYEAT, 2010, p. 172, nota 15.

${ }^{20} \mathrm{Cf}$. KRAUT, 2009, especialmente p. 92-94.

${ }^{21}$ Idem, p. 84. 
como uma boa resposta, esta será também para ela uma boa resposta. Para tanto, o estudante precisa dar peso às considerações dos outros tanto quanto às suas próprias sobre $\mathrm{o}$ assunto; ele precisa estar disposto a abandonar a sua posição caso alguma outra se revele, por meio de argumento, melhor do que a sua. Aquele que foi educado nos maus hábitos talvez dê mais peso às suas próprias opiniões simplesmente porque são suas e, por vaidade, pode recusarse a abandoná-las. Além disso, como afirma Kraut, "se alguém recebeu uma má educação e não reconhece isso, muitas proposições parecem-lhe verdadeiras e são incluídas entre os dados da sua teoria ética, mesmo que elas não mereçam ser consideradas seriamente" 22 , sendo o inverso igualmente possível, a saber, ele deixará de considerar seriamente teses e argumentos que merecem ser assim considerados, como, por exemplo, o argumento da função própria e a sua conclusão ${ }^{23}$.

É por essa razão que aquele que foi bem educado "possui ou pode facilmente apreender os princípios”, afirma Aristóteles em 1095b8. Isso significa que ele já concebe de forma explícita ou pode facilmente vir a assim conceber os princípios cujo conhecimento estamos buscando nesta investigação. Ele já pode, por exemplo, dispor da definição de eudaimonia (ele pode pensar que ser feliz é viver de acordo com a virtude; ou uma afirmação como essa é impossível para alguém que não fez a investigação proposta na $E N$ ?) ou pode vir a dela dispor por meio de argumento. Assim, lembrando do trecho anteriormente citado dos Primeiros Analíticos, deve-se dizer que aquele que tem experiência de algo tem por isso mesmo pelo menos em potência uma boa formulação dos princípios que a explicam, pois ele já pode dispor dessa boa formulação em ato, quando a investigação filosófica irá ajudá-lo apenas a tornar isso mais claro e a estabelecer a sua função enquanto princípio.

Após ter chegado à definição de eudaimonia em 1098a16-18, Aristóteles afirma: "Tampouco devemos exigir a causa da mesma forma em todas as questões; em alguns casos, basta que o que esteja bem estabelecido, como no caso dos princípios; o que é algo primeiro e um princípio" (1098a33-b3). Basta que tenhamos bem estabelecida e clara a definição de

\footnotetext{
22 Idem, p. 93.

${ }_{23}$ Deve ser lembrado que, embora Aristóteles não assinale isso, o argumento da função própria recebe já uma formulação bastante semelhante por Platão na República no final do livro I (cf. 352d-354c), o qual parece não convencer Trasímaco, que se retira da discussão no início do livro Il.
} 
eudaimonia: que ela é atividade da alma racional segundo perfeita virtude (1098a16-18). Essa definição, observa Aristóteles em 1098a22, nada mais é do que "um delineamento do bem"; os detalhes serão apresentados na sequência. A investigação recém iniciou, muito ainda precisa ser examinado. E devemos tomar o cuidado de não perder de vista o nosso objetivo principal, adentrando inutilmente na discussão de questões menores (1098a21-32).

A boa educação daquele que examina essas questões servirá como fundamento para reconhecer que o "o que é a eudaimoniă está bem estabelecido, ainda que esta seja uma formulação geral e deva ser mais especificada adiante, reconhecendo igualmente o alcance e a força que o argumento da função pode em relação a isso ter, razão pela qual, como foi afirmado em $E N$ I 4, ele não precisará de um porque. Ao dispensar um porque não penso que Aristóteles esteja afirmando que os quês, os princípios, não recebem ou não podem receber nenhum tipo de justificação filosófica, nenhum tipo de argumento, funcionando, por isso mesmo, como quês e princípios $^{24}$. Tampouco acredito, como fazem alguns comentadores, que Aristóteles dispensa o porque do estudante bem educado porque basta, para que ele realize tal investigação, que ele saiba que tais coisas são corretas ou justas (sendo assim aprendiz de virtude) e não por que elas são assim (sendo então prudente, phronimos); o porque será dado, assim é sugerido, ao menos parcialmente pela $E N^{25}$. Parece-me evidente que o aprendiz da $E N$ não

${ }_{24}$ É assim que Myles Burnyeat parece interpretar essa passagem. Para ele, no trecho "Ora, dos princípios, uns nós vemos por indução, outros por percepção, outros por um certo hábito e outros, ainda, de outras maneiras" (EN 1098b3-4), Aristóteles estaria assinalando que os princípios éticos são obtidos via habituação e não mediante argumento. É verdade que o que Burnyeat identifica aqui com os princípios certamente só é visto ou apreendido mediante o hábito, a prática na virtude, pois ele está se referindo às convicções do aluno sobre as ações nobres e justas (BURNYEAT, 2010, p. 160, nota 5). Estas convicções seriam archai enquanto pontos de partida para chegar a outros archai, i.e., as realidades mais fundamentais neste domínio. Não creio, no entanto, que esta seja a melhor maneira de ver essa passagem, embora ela seja evidentemente possível. Com efeito, a interpretação de Burnyeat requer que vejamos uma ambiguidade no uso do termo 'arche' e seus derivados em todo o trecho de EN I 4 1095a31-b8: por vezes Aristóteles usaria o termo se referindo aos pontos de partida da investigação, por vezes, aos princípios primeiros ou realidades mais fundamentais. A tradução de Ross visa, com efeito, a contemplar essa ambiguidade, traduzindo diferentemente o mesmo termo segundo o significado que supostamente deve ser-lhe atribuído ('first principles' nas linhas 1095a33 e 35; 'starting-point' nas linhas $1095 b 6$ e 8). Se, no entanto, mantivermos o mesmo sentido para 'arche' ao longo de toda a passagem, recusando ver uma ambiguidade sem nenhuma sinalização por parte de Aristóteles, e se recusarmos que é a essas convicções que Aristóteles está em 1098b3-4 fazendo referência com o termo 'princípios', mas a certas proposições que revelar-se-ão princípios ou realidades fundamentais no domínio da ação humana, então pode ser o caso destes quês terem origem no hábito e ainda assim receberem um ou mais argumentos em seu favor (como é o caso, com efeito, do estabelecimento de algo como um princípio em todo e qualquer domínio).

${ }^{25}$ Cf. BURNYEAT, 2010, p. 158; KRAUT, 2001, 248; LEAR, 1991, p.187; IRWIN, 1978, p. 262. 
precisa ser prudente, mas não penso que é a isso que Aristóteles está se referindo aqui. Que (hoti) e porque (dioti) são termos próprios a contextos que se referem a investigações, dos quais Aristóteles se ocupa, por exemplo, em Seg. An. I 13. Além disso, em momento algum na EN Aristóteles caracteriza o conhecimento prático do prudente como um conhecimento do porque, mas sim como um bem deliberar e agir em vista de bons fins ${ }^{26}$. Mas, ainda que possamos assim caracterizá-lo, a saber, como aquele que possui as boas razões para agir, não encontro em Aristóteles elementos suficientes para afirmar que uma explicação filosófica deve fazer parte das boas explicações que ele é capaz de dar acerca das suas decisões acertadas.

Assim, o alerta de Aristóteles em I 7 é para que não exijamos da mesma forma a causa em todas as questões, matérias ou domínios investigativos (cf. 1098a33), e é a esse alerta que creio que EN I 4 deve ser conectado. Um argumento em favor da definição apresentada foi oferecido e, Aristóteles adverte, ele carrega as razões adequadas pelas quais a sua conclusão deve ser afirmada. Exigir mais do que o que foi apresentado, pelo menos no momento (dado que maiores especificações serão feitas ao longo da investigação), seria falta de educação no assunto.

Em I 6 da Ética Eudêmia, Aristóteles faz uma afirmação semelhante. É bem verdade que o filósofo não deve afirmar nada sem ter razões para tanto, mas a busca pela justificação deve ser feita com cautela:

“(...) mesmo com relação às coisas políticas não se deve considerar supérfluo um tal exame, pelo qual não apenas o $O$ que será evidente, mas também o porquê (pois é filosófico um tal exame em cada investigação). Isso, no entanto, exige muita cautela, pois, por parecer que é próprio do filósofo o nada falar a esmo e sim com razão, existem os que frequentemente passam despercebidos ao apresentar razões inadequadas ao tema e vazias (...). Sofrem tais coisas por falta de instrução, pois é falta de instrução não ser capaz de julgar a respeito de cada assunto quais são as razões que lhe são apropriadas e quais são inadequadas. (grifos meus; 1216b37-1217a10)”

Dispensar um porque no caso do conhecimento dos princípios não é incompatível com o que é dito no trecho acima. Também no caso das coisas

${ }^{26}$ Cf. EN VI 5. 
práticas ou políticas as razões ou causas precisam ser apresentadas, se seus argumentos devem ser filosóficos. Devemos saber também por que a eudaimonia é como é. Mas não devemos nos perder na busca por esse conhecimento: as causas a serem buscadas devem ser apropriadas e não inadequadas ao tema ou vazias. São essas causas inadequadas e vazias as que foram dispensadas em $E N$ I 4, ao dizer que o estudante não precisará de um porque e não as adequadas e necessárias para se ter uma compreensão filosófica da felicidade.

Em consonância com tudo isso, Aristóteles segue afirmando na $E N$ que "devemos tentar investigar cada conjunto de princípios da maneira natural” (1098b4), buscando e apresentando as causas onde elas podem e/ou devem ser buscadas e apresentadas, "esforçando-nos por delimitá-los corretamente, uma vez que têm grande influência no que segue” (1098b6). Pois "o início é pensado ser mais da metade do todo e muitas das questões que fazemos são esclarecidas por ele" (1198b5-8). Nos capítulos 8 e 9 do livro I, Aristóteles procura mostrar como a definição encontrada, sendo bastante geral, está em harmonia com as diversas opiniões acerca da eudaimonia; nos capítulos 10-12, ele mostra como ela responde ou pelo menos indica um caminho de resposta para algumas questões controversas (por exemplo, se a sorte dos descendentes afeta ou não a felicidade dos mortos). Tudo isso funciona como uma argumentação em favor da pertinência e correção da definição bastante geral de eudaimonia extraída do argumento da função própria.

Volto a $E N$ I 4 a fim de finalizar minhas considerações. Aristóteles encerra as observações sobre os requisitos do bom estudante das lições da $E N$ e sobre a direção a que a última se dirige com um trecho do Os trabalhos e os dias de Hesíodo:

"Certamente, o melhor [homem] é aquele que conhece por si todas as coisas;

Bom, aquele que ouve quando os homens aconselham bem; Mas aquele que não sabe nem adota de coração

A sabedoria de um outro, é uma criatura inútil.” (1095b10-13)

Aquele que leva em conta as coisas aprendidas pela sua experiência em um determinado domínio, chega a certas definições - os quês - e não precisa de porquês - que os justificariam de maneira externa e inapropriada, ou seja, não os justificariam. Se ele já chegou a tais definições por refletir por si ou é 
capaz de a elas chegar por seguir os argumentos propostos por Aristóteles na $E N$, ele conhece atual ou potencialmente os princípios da disciplina em questão; ele "conhece por si todas as coisas". Já aquele que não puder chegar a essas definições porque a sua experiência é insuficiente ou porque conduziu mal a sua vida, não poderá adquirir a ciência em questão, mas poderá "adotar de coração a sabedoria de um outro", desde que ele seja capaz de reconhecer a sua experiência como insuficiente ou a sua vida como má ${ }^{27}$. Adotar a sabedoria de um outro não é ser sábio, como lemos no poema de Hesíodo, mas ser capaz de reconhecer em um outro a sabedoria que ele não é capaz de adquirir.

Devemos lembrar que um direcionamento para a vida, ainda que "muito amplo e em linhas gerais" (EN 1094b20), pois "os agentes devem eles mesmos considerar o que é apropriado à ocasião" (EN 1104a9-10), é o objetivo último visado pelo conhecimento obtido na $E N$; sem alcançar isso, a empreitada total proposta na $E N$ não obteve sucesso. Haverá, assim, aqueles que, não sendo capazes de adquirir tal conhecimento, serão apesar disso capazes de deixar-se guiar por quem o possui. Entretanto, haverá aqueles que, por não possuírem a experiência suficiente ou a adequada e não serem capazes de reconhecer isso, não serão nem mesmo capazes de delegar o direcionamento (mesmo que bastante geral) ao conhecimento de um outro: eles serão considerados, "criaturas inúteis".

É de maneira semelhante que Santo Tomás entende a referência de Aristóteles a Hesíodo. Diz ele que "o homem que não é capaz de conhecer por si nem de adotar o que ouve de um outro, é um inútil, na medida em que a aquisição de uma ciência está em questão"28. Quem não observa e se familiariza com os objetos astronômicos não pode aprender os seus princípios, não pode tornar-se astrônomo. Quem não observa e não se familiariza com os objetos médicos - observação de doenças, tratamentos, estados de recuperação, resultados saudáveis, etc. - não pode aprender os princípios médicos, não pode tornar-se médico. Mas não será um “inútil” se, quando estiver doente, se deixar guiar por aquele que sabe, i.e., se fizer as

\footnotetext{
${ }^{27} \mathrm{Cf}$. aqui, p. 11, onde apresento uma passagem em que Kraut sugere essa possibilidade: "se alguém recebeu uma má educação e não reconhece isso" etc. (KRAUT, 2009, p. 93). A possibilidade de viver mal, reconhecer isso e reconhecer que a mudar não é mais possivel, está em aberto para um agente. E, se a situação é tal que o impede de aprender os princípios da boa vida, ele pode vir a confiar no conhecimento daquele que é capaz de aprendê-los.

${ }^{28}$ AQUINO, 1961, Book I, Lecture IV, § 54, grifos meus.
} 
coisas que o médico prescreve. Da mesma forma, quem não tem experiência na virtude e nas ações não pode aprender os princípios da boa vida; não pode, portanto, tornar-se filósofo moral ou político. Mas será um inútil ou "peso morto" (conforme a tradução de Ross) caso não seja ao menos capaz de deixar-se guiar por aqueles capazes de assim se tornarem em virtude do conhecimento que os qualifica como tais.

\section{Conclusão}

Como pretendi deixar claro, fazer ciência para Aristóteles é, como Sócrates e Platão o ensinaram, buscar pelos princípios. Alguns desses princípios são definições e elas deverão ser buscadas por aquele que pretende, em certo domínio, conhecer. Mas elas não devem ser buscadas de qualquer forma, apelando para padrões de exatidão abstratos ou absolutos. É para a natureza do objeto investigado que deve atentar o investigador a fim de saber o tipo de exatidão que ele está autorizado a busca nessa empreitada. Além disso, também a direção em que o investigador avança é a notada por Platão: estamos indo na direção dos princípios quando iniciamos a busca pelo conhecimento do que quer seja; é apenas depois de conhecê-los que podemos tentar o caminho de volta, demonstrando as realidades que dele dependem. O nosso ponto de partida - o "o mais conhecido para nós" - não é, portanto, uma espécie de escada que jogamos fora depois de alcançar os princípios - o "o que é mais conhecido sem mais", pois os princípios funcionarão como explicações e justificativas justamente da nossa experiência. Para Aristóteles, diferentemente de Platão, as coisas são, em sua grande maioria, como elas aparecem para nós. O que precisamos é, portanto, explicar como elas são através dos seus princípios primeiros.

\section{Referências Bibliográficas}

ARISTÓTELES. The Nicomachean Ethics (Trad. D. W. Ross). Oxford: Oxford University Press, 1998.

. Metaphysics (Trad. D. W. Ross). In: BARNES, J. (ed.). The Complete Works of Aristotle. Vol. II. Princeton: Princeton University Press, 1995.

. Prior Analytics (Trad. A. J. Jenkinson). In: BARNES, J. (ed.). The

Complete Works of Aristotle. Vol. I. Princeton: Princeton University Press, 1995. 
. Seconds Analytics (Trad. J. Barnes). In: BARNES, J. (ed.). The Complete Works of Aristotle. Vol. I. Princeton: Princeton University Press, 1995

Topics (Trad. W. A. Pickard-Cambridge). In: BARNES, J. (ed.), The Complete Works of Aristotle. Vol. I. Princeton: Princeton University Press, 1995.

. Física I e II (Introdução, tradução e comentários de Lucas Angioni). Campinas: Editora da Unicamp, 2009.

inédita).

. Ética Eudêmia (Trad. I. Zanuzzi; R. Zillig (Versão provisória e

BURNYEAT, M. F. "Aprender a ser bom segundo Aristóteles". In: ZINGANO, M. (org.). Sobre a Ética Nicomaqueia de Aristóteles. São Paulo: Odysseus, 2010, p. 155-182.

IRWIN, T. "First Principles in Aristotle's Ethics". Midwest Studies in Philosophy, vol. III (1978), p. 252-272.

. Plato's Ethics. Oxford: Oxford University Press, 1995.

KRAUT, R. "Como justificar proposições éticas: o método de Aristóteles". In: KRAUT, R. (ed.). Aristóteles: A Ética a Nicômaco. Porto Alegre: Artmed, 2009, p. 77-94.

. "Aristotle on Method and Moral Education". In: Gentzler, J. (ed.). Method in Ancient Philosophy. Oxford: Clarendon Press, 2001, p. 271290;

LAWRENCE, G. "O bem humano e a função humana". In: KRAUT, Richard. (ed.). Aristóteles: A Ética a Nicômaco. Porto Alegre: Artmed, 2009, p. 42-76.

LEAR, J. Aristotle: the desire to understand. Cambridge: Cambridge University Press, 1991.

MOSQUERA, G. "L'argument logikos chez Aristote”. Les Études Classiques, 66 (1998), p. 33-52.

OWEN, G. E. L. "Tithenai ta phainomena”. In: BARNES, J., SCHOFIELD, M., SORABJI, R. (eds.). Articles on Aristotle I - Science. London: Duckworth, 1975, p. 113-126.

PLATÃO. A República. Lisboa: Fundação Calouste Gulbenkian. 12.ed. 2010.

SIM, M. From puzzles to principles? - Essays on Aristotle's Dialectic. Lanham: Lexington Books, 1999.

SPINELLI, P. T. "O que significa compreender a Ética Nicomaqueia de Aristóteles?” In: Philósophos, v. 15 (2010), p. 147-167. 
TOMPAS DE AQUINO. Commentary on the Nicomachean Ethics (Trans. C. I. Litzinger). Chicago: Henry Regenery Company, 1961.

E-MAIL: ptspinelli@gmail.com

RECEBIDO: Outubro/2012 APROVADO: Novembro/2012 